Gut, 1986, 27, 1101-1105

Case reports

\title{
Budd-Chiari syndrome presenting as fulminant hepatic failure
}

\author{
P R POWELL-JACKSON, R J EDE, AND ROGER WILLIAMS \\ From the Liver Unit, King's College School of Medicine and Dentistry, Denmark Hill, London
}

SUmmary Two cases of the Budd-Chiari syndrome are described in whom the diagnosis was finally confirmed at necropsy. The presentation was with encephalopathy, occurring within eight weeks of first symptoms and coming therefore within the definition of fulminant hepatic failure. In one, thought to have non- $A$, non-B hepatitis, encephalopathy progressed to grade 4 coma with death 12 days after presentation. In the other, mistakenly thought to have intra-abdominal malignancy, an exploratory laparotomy exacerbated the encephalopathy with death three weeks later. In neither case were non-invasive investigations, such as ultrasound and isotope scanning, carried out which might have facilitated an earlier diagnosis and consideration for orthotopic liver transplantation, probably the most appropriate form of therapy for these very severe cases.

Most cases of the Budd-Chiari syndrome present with a subacute illness characterised by painful hepatomegaly and tense ascites. In occasional instances the diagnosis may be made during the investigation of an apparent cryptogenic cirrhosis but, in the present report, we describe two cases presenting at the other end of the spectrum. These patients developed hepatic encephalopathy within eight weeks of first symptoms of the illness and without evidence of previous liver disease, and come within the definition of fulminant hepatic failure. ${ }^{1}$ As this mode of presentation is not described in any of the published series, ${ }^{2-5}$ we have considered the diagnostic difficulties posed by these two cases and the possible treatment measures.

\section{Case reports}

CASE 1

A 27 year old man was admitted to hospital on 30 May, 1980 with an eight day history of lower abdominal pain, vomiting, and watery brown diarrhoea. Over the next two days he became progressively oliguric and drowsy with blood cultures sterile

Address for correspondence: Dr Roger Williams FRCP, Liver Unit, King's College School of Medicine and Dentistry, Denmark Hill, London SE5 8RX.

Received for publication 13 December 1985. on two occasions. On transfer to this Unit on 3 June, he was in grade IV encephalopathy, deeply jaundiced, hyperventilating and hyperreflexic. The liver was impalpable and the spleen enlarged $5 \mathrm{~cm}$ below the left costal margin. The abdomen was not distended and had minimal shifting dullness in the flanks.

Investigations carried out after transfer to this Unit showed a normal haemoglobin concentration of $14.6 \mathrm{~g} / \mathrm{dl}$. a raised white cell count of $35.9 \times 10^{9} / 1$ with a neutrophilia of $86 \%$ and left shift. The prothrombin time was 45 seconds (control 12 seconds). There was evidence of a metabolic acidosis and renal failure with the following plasma concentrations: sodium $127 \mathrm{mmol} / \mathrm{l}$, potassium $5.7 \mathrm{mmol} / \mathrm{l}$, bicarbonate $13 \mathrm{mmol} / \mathrm{l}$, creatinine $1018 \mu \mathrm{mol} / \mathrm{l}$, glucose $9.8 \mathrm{mmol} / \mathrm{l}$. Arterial blood gases on air: $\mathrm{PO}_{2} 10 \cdot 81 \mathrm{kPa}, \mathrm{PCO}_{2} 3.41 \mathrm{kPa}, \mathrm{pH} 7 \cdot 32$, standard bicarbonate $-11.5 \mathrm{mmol} / \mathrm{l}$. Liver function tests: bilirubin $316 \mu \mathrm{mol} / \mathrm{l}$, alkaline phosphatase $270 \mathrm{IU} / \mathrm{l}$, aspartate aminotransferase $353 \mathrm{IU} / \mathrm{l}$, total protein $55 \mathrm{~g} / \mathrm{l}$ and albumin $30 \mathrm{~g} / \mathrm{l}$. Serum immunoglobulin, copper and caeruloplasmin concentrations were normal and serological tests for hepatitis $A$ and B, Epstein Barr virus, cytomegalovirus, toxoplasma and leptospirosis were negative. The urine:plasma osmolality ratio was less than $1 \cdot 1: 1$. Microscopic examination of an ascitic tap revealed scanty gram positive cocci and blood cultures grew Strep faecalis. 
$\mathrm{He}$ was treated with intravenous antibiotics (ampicillin, cefuroxime, and metronidazole) and our standard anti-liver failure regimen. ${ }^{6}$ Haemodialysis was started but, after 24 hours, pupillary responses became unequal because of cerebral oedema and mechanical ventilation became necessary because of deteriorating blood gases. Death occurred on 10 June.

\section{LIVER PATHOLOGY}

A percutaneous liver biopsy obtained immediately after death showed features of acute outflow venous block with confluent areas of haemorrhagic necrosis which in places involved all zones of the liver acinus (Fig. 1). At necropsy there were three litres of slightly blood stained ascitic fluid and the liver was enlarged (weight $2600 \mathrm{~g}$ ), its cut surface showing patchy congestion particularly around branches of the hepatic veins. The latter contained thrombi undergoing various degrees of organisation with some completely fibrosed. The orifices of the hepatic veins were small and scarred and contained recent thrombus. The spleen was enlarged (weight $830 \mathrm{~g}$ ), firm and congested, with numerous haemorrhagic infarcts.

\section{CASE 2}

A 43 year old woman was admitted to her local hospital on 30 June, 1978 with a two day history of abdominal pain and distension preceded for five days by diarrhoea and vomiting. On examination she was drowsy, confused, and disorientated. The abdomen was distended and tender in the right upper quadrant and there was shifting dullness but no masses were felt.

Investigations showed a raised haemoglobin concentration of $17.6 \mathrm{~g} / \mathrm{dl}$, a raised white cell count of $34.9 \times 10^{9} / 1$ with a neutrophilia of $83 \%$ and left shift. Liver function tests showed evidence of acute hepatocellular injury: bilirubin $48 \mu \mathrm{mol} / 1$, alkaline phosphatase $130 \mathrm{IU} / \mathrm{l}$, aspartate aminotransferase $936 \mathrm{IU} / 1$, total protein $60 \mathrm{~g} / 1$ and albumin $34 \mathrm{~g} / \mathrm{l}$.

A diagnosis of intra-abdominal malignancy was made and laparotomy was undertaken three days later. At operation, the liver and spleen were both tense, smooth and enlarged and there was no evidence of malignancy. The ascites was gross and during the subsequent eight days it rapidly reaccumulated and leaked through the wound. There was a concomitant fall in serum sodium concentration to $94 \mathrm{mmol} / \mathrm{l}$ and rise in potassium to

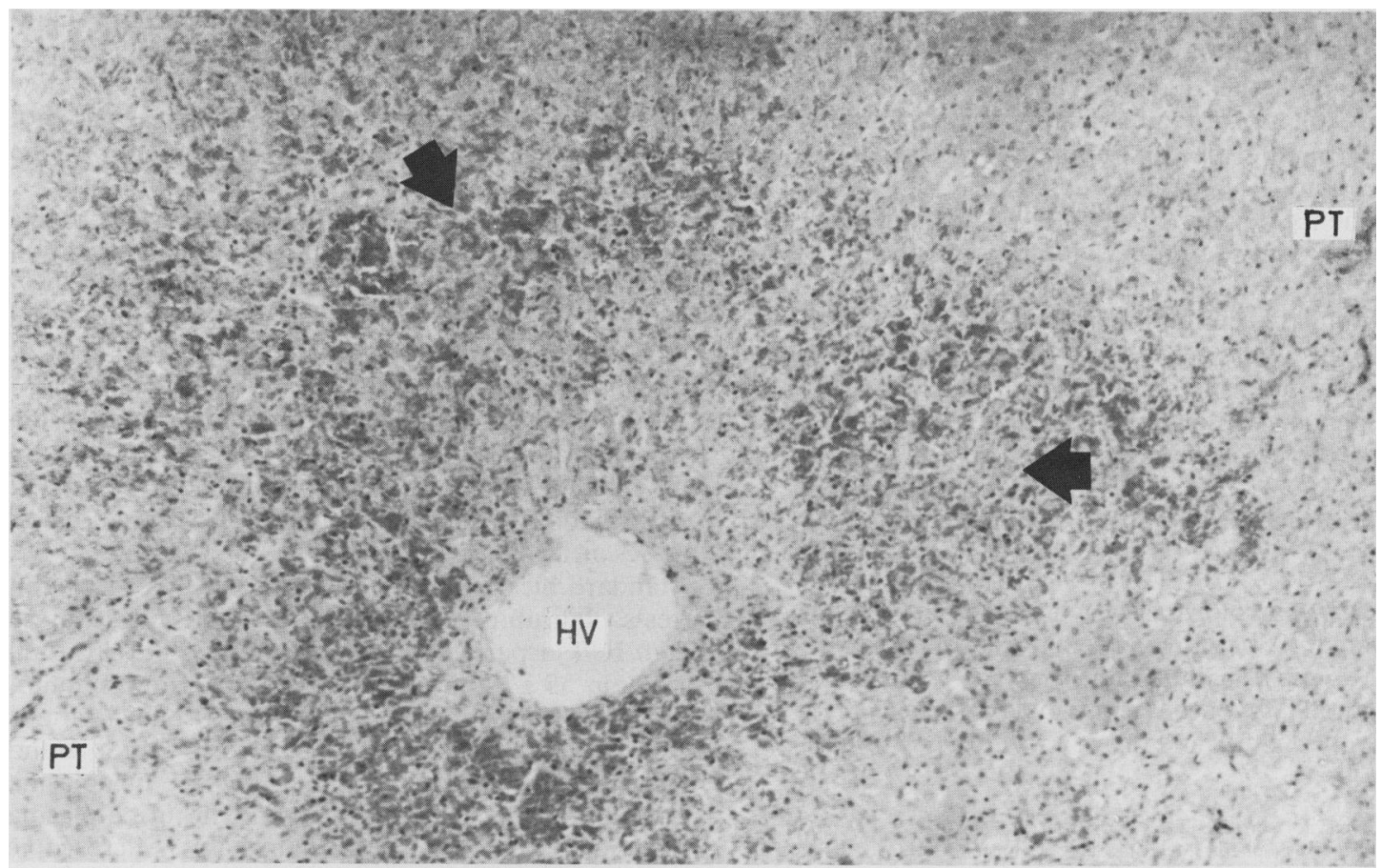

Fig. 1 Liver obtained by percutaneous biopsy in patient 1. There are features of acute outflow venous block with confluent areas of haemorrhagic necrosis (arrowed). HV: hepatic venule. PT: portal tract. $H$ and $E$. 

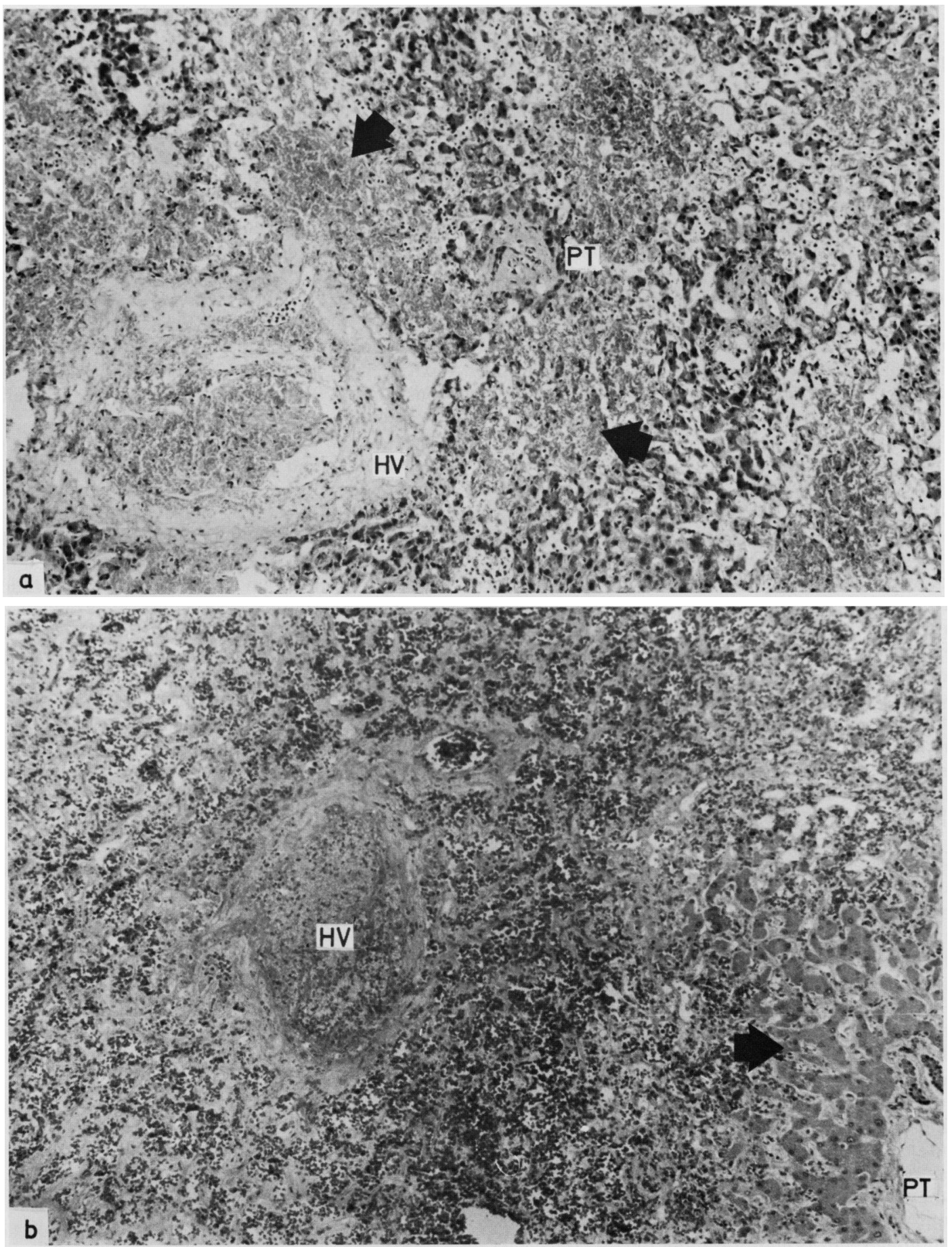

Fig. 2a Liver taken at surgery in patient 2. There is extensive hepatocyte loss and congestion throughout zones 2 and 3 (arrowed). Note a fresh thrombus obliterating an hepatic vein branch (HV). PT: portal tract. H and E.

Fig. $2 \mathrm{~b}$ Liver at post mortem from the same patient as Fig. 2a. There are only occasional islands of surviving hepatocytes (arrowed) around portal tracts (PT). $H V$ :hepatic vein. $H$ and $E$. 
$7 \cdot 2 \mathrm{mmol} / \mathrm{l}$. At the time of transfer to King's College Hospital the patient had developed worsening encephalopathy and evidence of functional renal failure. Liver function tests had deteriorated: bilirubin $580 \mu \mathrm{mol} / \mathrm{l}$, alkaline phosphatase $330 \mathrm{IU} / \mathrm{l}$, aspartate aminotransferase $371 \mathrm{IU} / 1$, total protein $52 \mathrm{~g} / 1$, albumin $25 \mathrm{~g} / \mathrm{l}$, prothrombin time 35 seconds (control 13 seconds).

She was treated with intravenous antibiotics, salt poor albumin, sodium and protein restriction, and an infusion of streptokinase and plasminogen. The latter was stopped after 24 hours because of widespread bleeding which continued for a further 12 hours. Despite these measures she became progressively more jaundiced over the 12 days (bilirubin concentration rising to $1050 \mu \mathrm{mol} / \mathrm{l}$ ) and died after an upper gastrointestinal bleed.

\section{LIVER PATHOLOGY}

A wedge biopsy obtained at laparotomy showed the features of outflow venous block with extensive liver cell loss throughout zones 2 and 3 , and fresh thrombus in some venules (Fig. 2a). At necropsy the liver was shrunken $(1250 \mathrm{~g})$ except for the caudate lobe which was enlarged, tense, and congested. The left hepatic vein contained organised mural thrombus although the lumen was patent. The right hepatic vein was patent. Microscopic examination of the liver showed areas of haemorrhagic necrosis involving all zones of the lobule (Fig. 2b). The spleen was congested (weight $290 \mathrm{~g}$ ) and contained one haemorrhagic infarct. Sections of bone marrow showed complete replacement by hypercellular haemopoietic tissue consistent with polycythaemia rubra vera.

\section{Discussion}

The diagnosis made during life in the first case was that of fulminant hepatic failure from non-A, non-B infection, the classical features of the Budd-Chiari syndrome of tender hepatomegaly and tense ascites being conspicuously absent. In retrospect, greater attention should have been paid to the finding of splenomegaly as the degree of enlargement present is unusual in fulminant viral hepatitis, although it is to be found in about a third of patients with the Budd-Chiari syndrome. ${ }^{3}$ In the second case, the confidence with which signs of tender hepatomegaly and ascites were attributed to intra-abdominal malignancy was such that the surgeon did not request any non-invasive investigations of the liver. Abdominal ultrasound examination and/or ${ }^{99 \mathrm{~m}} \mathrm{Tc}$ sulphur colloid scintigraphy of the liver are likely to have given a positive lead to the diagnosis of the Budd-Chiari syndrome and thereby prevented the unnecessary laparotomy which was so deleterious. Since 1972, eight other patients with this disease have been referred to this Unit because of rapid deterioration after laparotomy and all developed renal impairment or severe electrolyte abnormalities. Two of them became mildly encephalopathic after surgery although, in contrast with the cases reported here, there was no evidence of encephalopathy before surgery. The detrimental consequences of laparotomy are related to the effect of general anaesthesia on hepatic blood flow ${ }^{7}$ and to the fluid and electrolyte changes resulting from the loss of ascitic fluid at operation and subsequently because of leakage through the abdominal wound. Hepatic decompensation with the development of encephalopathy after laparotomy has been described previously in the Budd-Chiari syndrome $e^{5-10}$ as well as in acute hepatitis and cirrhosis. ${ }^{10}$

In the two cases reported here in which the presentation came within the definition of fulminant hepatic failure, there was biochemical and histological evidence of very extensive haemorrhagic infarction of the liver. This is consistent with the observation that in the more acute cases, the abnormalities in serum transaminase concentrations and prothrombin time are greatest. ${ }^{4}$ The evidence at necropsy for earlier and clinically silent episodes of hepatic vein thrombosis have also been reported in the more typical subacute and chronic cases. ${ }^{2}$

The only possible treatment in our view for such cases is hepatic transplantation. Decompression of the portal system by shunting would be expected to carry a very high mortality in the presence of such extensive hepatic necrosis, and the encouraging experience to date with orthotopic liver transplantation in fulminant and subacute hepatic failure from other causes would point to this as being the more appropriate line of therapy. ${ }^{11}$

The authors are indebted to Dr Bernard Portmann, Consultant Histopathologist, for the histological assessments.

\section{References}

1 Trey C, Davidson CC. The management of fulminant hepatic failure. In: Popper H, Schaffner F, eds. Progress in liver diseases. Vol. III, New York: Grune and Stratton, 1970: 292-8.

2 Parker RGF. Occlusion of the hepatic veins in man. Medicine (Balt) 159; 38: 369-402.

3 Tavill AS, Wood EJ, Kreel L, et al. The Budd-Chiari syndrome: correlation between hepatic scintigraphy and the clinical, radiological and pathological findings in nineteen cases of hepatic venous outflow obstruction. Gastroenterology 1975; 68: 509-18. 
4 Powell-Jackson PR, Melia W, Canalese J, et al. BuddChiari syndrome: clinical patterns and therapy. $Q J$ Med 1982; 51: 79-88.

5 Langer B, Stone R, Colapinto R, et al. Clinical spectrum of the Budd-Chiari syndrome and its surgical management. Am J Surg 2975; 129: 137-45.

6 Williams R. The management of liver failure. In: Weatherall DJ, ed. Advanced medicine. Vol. 14 London: Pitman Medical, 1978: 19-29.

7 Strunin L. Anaesthetic management of patients with liver disease. In: Wright R, Alberti KGMM, Karran S et al, eds. Liver and biliary disease London: Saunders, 1979.
8 Bethelot P, Mignon F, Maillard JN. Syndrome aigu de Budd-Chiari. Aspects cliniques et biologiques de deux observations. Rev Med Chir Mal Foie 1969;44: 25-8.

9 Sandle G, Layton M, Record C, et al. Fulminant hepatic failure due to Budd-Chiari syndrome. Lancet $1980 ;$ i: 1199.

10 Powell-Jackson PR, Greenway B, Williams R. Adverse effects of exploratory laparotomy in patients with unsuspected liver disease. Br J Surg 1982; 69: 449-51.

11 Williams R, Gimson AES. An assessment of orthotopic liver tranplantation in acute liver failure. Hepatology 1984; 4: 22S-4S. 